\title{
Bias-free photoelectrochemical water splitting with photosystem II on a dye-sensitised photoanode wired to hydrogenase
}

Katarzyna P. Sokol ${ }^{1}$, William E. Robinson ${ }^{1}$, Julien Warnan ${ }^{1}$, Nikolay Kornienko ${ }^{1}$, Marc M. Nowaczyk ${ }^{2}$, Adrian Ruff ${ }^{3}$, Jenny Z. Zhang ${ }^{1}$ and Erwin Reisner ${ }^{1, *}$

(1) Department of Chemistry, University of Cambridge, Lensfield Road, Cambridge CB2 $1 \mathrm{EW}, \mathrm{UK}$

(2) Plant Biochemistry, Faculty of Biology \& Biotechnology, Ruhr-Universität Bochum, Universitätsstr. 150, 44780 Bochum, Germany

(3) Analytical Chemistry - Center for Electrochemical Sciences (CES), Faculty of Chemistry and Biochemistry, Ruhr-Universität Bochum, Universitätsstr. 150, 44780 Bochum, Germany

*Corresponding author: reisner@ch.cam.ac.uk 


\section{Abstract}

Natural photosynthesis stores sunlight in chemical energy carriers, but it has not evolved for the efficient synthesis of fuels, such as $\mathrm{H}_{2}$. Semi-artificial photosynthesis combines the strengths of natural photosynthesis with synthetic chemistry and materials science to develop model systems that overcome Nature's limitations, such as low-yielding metabolic pathways and non-complementary light absorption by Photosystem (PS) I and II. Here, we report a bias-free semi-artificial tandem platform that wires PSII to hydrogenase for overall water splitting. This photoelectrochemical cell integrated the red and blue light-absorber PSII with a green light-absorbing diketopyrrolopyrrole dye-sensitised $\mathrm{TiO}_{2}$ photoanode enabling complementary panchromatic solar light absorption. Effective electronic communication at the enzyme-material interface was engineered using an Os complex-modified redox polymer on a hierarchically-structured $\mathrm{TiO}_{2}$. This system provides a design protocol for bias-free semi-artificial Z-schemes in vitro and provides an extended toolbox of biotic and abiotic components to re-engineer photosynthetic pathways. 
Semi-artificial photosynthesis bridges the rapidly progressing fields of synthetic biology and artificial photosynthesis, offering a platform for developing and understanding solar fuel generation ${ }^{1-4}$. Synthetic biology has vastly opened up the way Nature can be manipulated to streamline functionality and to build artificial biological systems, but its complex machineries and metabolic pathways limit engineering flexibility ${ }^{5}$. Artificial photosynthesis utilises synthetic, often biomimetic, components to convert and store solar energy, but is often constrained by inefficient catalysis and costly/toxic materials ${ }^{6}$. Semi-artificial photosynthesis aims to integrate the high efficiency and selectivity of enzymes with the controllability of synthetic materials to photocatalyse endergonic reactions in the absence of competing processes ${ }^{7}$. It also allows the construction of biologically inaccessible pathways with a high level of control and flexibility ${ }^{3}$. The catalytic activity of redox enzymes can be harnessed when adsorbed on electrodes by protein film electrochemistry (PFE) and photoelectrochemistry (PF-PEC) $)^{8,9}$. A key challenge is to design biotic-abiotic interfaces that effectively wire together the biological and synthetic components to operate at their optimum.

Solar-driven water splitting into $\mathrm{H}_{2}$ and $\mathrm{O}_{2}$ is the most prominent model reaction in artificial photosynthesis ${ }^{10}$. Inefficient catalysis (particularly, kinetically slow $\mathrm{O}_{2}$ evolution and formation of partially oxidised side products) is a major limitation in synthetic systems, resulting in the requirement of large overpotentials and energy conversion losses ${ }^{6}$. Oxygenic organisms convert solar energy using a photosynthetic Z-scheme containing two light absorbers, Photosystem (PS) I and II ${ }^{11}$. In this tandem configuration, the first excitation in PSIl drives water oxidation to $\mathrm{O}_{2}$ and produces a proton gradient, whereas the second excitation in PSI generates a low potential electron to drive $\mathrm{CO}_{2}$ fixation into sugars ${ }^{12}$. Alternatively, $\mathrm{H}_{2}$ can be produced from microalgae and cyanobacteria, via electron transfer from ferredoxin to a [FeFe]- 
hydrogenase ([FeFe]- $\mathrm{H}_{2}$ ase), reducing protons to $\mathrm{H}_{2}{ }^{13}$. Efficiencies for photobiological $\mathrm{H}_{2}$ production are low for several reasons ${ }^{14,15}$. First, PSII and PSI overlap in light absorption and compete for a small fraction of the solar spectrum. Second, high light intensities limit efficient electron flux up and down-stream of PSII. Third, in vivo $\mathrm{H}_{2}$ production relies on $\mathrm{O}_{2}$-sensitive [ $\left.\mathrm{FeFe}\right]-\mathrm{H}_{2}$ ases, preventing sustained water splitting. Fourth, $\mathrm{CO}_{2}$ fixation is preferred over proton reduction leading to low $\mathrm{H}_{2}$ yields. Overcoming these limitations offers scope for enhancing $\mathrm{H}_{2}$ production with biological components.

We have previously reported a PEC water splitting system with a PSII photoanode wired to a $[\mathrm{NiFeSe}]-\mathrm{H}_{2}$ ase cathode ${ }^{3}$. However, this system relied solely on light absorption by PSII and required an externally applied voltage due to the low electrochemical potential of electrons leaving PSII. This limitation can be resolved by introducing a second light absorber to further promote the energetics of the electrons to be delivered to $\mathrm{H}_{2}$ ase ${ }^{16}$. To generate sufficient driving force for overall water splitting while maximising solar energy harvesting, complementary dual-absorber/tandem systems can be assembled, showing theoretical limits for solar-to-hydrogen (STH) efficiency of up to $25 \%{ }^{17}$. PSII ${ }^{18,19}$ and $\mathrm{BiVO}_{4}{ }^{20}$ photoanodes wired to PSI photocathodes have been reported to produce electricity, but no chemical fuel. Tandem systems containing PSII have not been combined with enzymatic fuel synthesis ${ }^{21-23}$.

Herein, a semi-artificial system for unassisted photocatalytic water splitting with PSII and $\mathrm{H}_{2}$ ase is presented. This PEC system does not require an external energy input as dual light absorption is realised by a tandem photoanode consisting of PSII wired to a dye-sensitised $\mathrm{TiO}_{2}$, providing sufficient voltage to reduce protons using a $\mathbf{H}_{2}$ ase cathode. This PEC design is inspired by dye-sensitised solar cells ${ }^{24,25}$, and allows 
replacing PSI by a rationally-designed diketopyrrolopyrrole (dpp) dye with an absorption complementary to PSII. Efficient electronic communication between PSII and dpp was achieved by using the redox polymer poly(1-vinylimidazole-coallylamine)-Os(bipy) ${ }_{2} \mathrm{Cl}$ (Pos), which bypasses possible limitations from inefficient interfacial electron transfer. Simultaneously, the hydrogel character of the redox polymer provides a solvated environment for the biocatalyst. A hierarchicallystructured inverse opal $\mathrm{TiO}_{2}\left(\mathrm{IO}-\mathrm{TiO}_{2}\right)$ scaffold was employed to provide high surface area for effective integration of polymer/PSII. 


\section{Assembly of the tandem PSII-dye photoanode}

The components and assembly of the PEC tandem cell is depicted in Fig. 1 and the principle of operation as a semi-artificial Z-scheme is shown in Supplementary Fig.

1. Hierarchically-structured $\mathrm{IO}-\mathrm{TiO}_{2}$ electrodes were assembled on a $\mathrm{TiO}_{2}$ layerprotected fluorine tin oxide (FTO)-coated glass substrate via a modified co-assembly method (Supplementary Fig. 2) ${ }^{3}$. The $\mathrm{TiO}_{2}$ protection layer was used to prevent direct contact of electroactive components (PSIl and Pos) with the FTO. The optimal thickness of the $1 \mathrm{O}-\mathrm{TiO}_{2}$ film was determined to be $20 \mu \mathrm{m}$, based on preliminary electrochemical screening, and was utilised throughout this work ${ }^{4}$. Scanning electron microscopy (SEM) revealed a diameter of $750 \mathrm{~nm}$ for the $\mathrm{TiO}_{2}$ macropores with connecting channels of $150 \mathrm{~nm}$ and a mesoporous skeleton with a porosity of approximately $50 \mathrm{~nm}$. The macroporosity permits the penetration of the bulky PSII and Pos ( 20 nm and $16 \mathrm{~nm}$ in size, respectively $)^{3,4}$, whereas the mesoporous structure provides enhanced effective surface area for guest adsorption.

Dye-sensitisation of the $1 \mathrm{O}-\mathrm{TiO}_{2}$ photoanodes $\left(A=0.25 \mathrm{~cm}^{2}\right)$ was performed by soaking $1 \mathrm{O}-\mathrm{TiO}_{2}$ in a tetrahydrofuran (THF) solution of dpp $\mathbf{p}^{26,27}$ overnight (Supplementary Fig. 3). The resulting $\mathrm{IO}-\mathrm{TiO}_{2} \mid \mathbf{d p p}$ electrodes had a dpp surface loading of $72 \pm 4 \mathrm{nmol} \mathrm{cm}{ }^{-2}$ (estimated by spectrophotometry; Supplementary Fig. 4), consistent with previously reported loadings of molecular species on mesoporous metal oxide scaffolds ${ }^{28}$. The organic dpp dye was selected for its complementary absorption spectrum to PSII and for its ability to act as an efficient visible-light photosensitiser for $\mathrm{TiO}_{2}$ in aqueous media, chemisorbing via its phosphonic acid anchoring group ${ }^{27}$. For comparison, electrodes were also prepared using the ruthenium bis(2,2'-bipy)(4,4'-bis(phosphonic acid)-2,2'-bipy) dibromide dye (RuP; bipy 
$=2,2^{\prime}$-bipyridine $)^{29-32}$, which is commonly used as a benchmark in aqueous dyesensitised schemes (Supplementary Figs. 1c and 3).

The macroporous voids of the $1 \mathrm{O}-\mathrm{TiO}_{2} \mid \mathrm{dpp}$ electrodes were subsequently filled with a

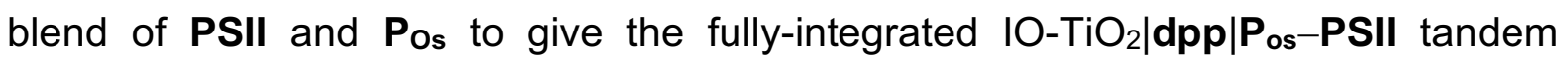
photoanode. PSII chosen for this study was isolated from the thermophilic cyanobacterium Thermosynechococcus elongatus as a well characterised ${ }^{33,34}$, highly active and relatively robust PSII variant ${ }^{35,36}$. Loadings of $24 \pm 4 \mathrm{nmol} \mathrm{cm}^{-2}$ and $143 \pm$ $25 \mathrm{pmol} \mathrm{cm}^{-2}$ were determined by inductively-coupled plasma optical emission spectroscopy (ICP-OES) and Ultraviolet-Visible (UV-Vis) spectrophotometry for Pos and PSII, respectively (Supplementary Fig. 4). The redox polymer Pos mediates electron transfer between $\mathbf{P S I I}$ and the $\mathrm{IO}_{-} \mathrm{TiO}_{2} \mid \mathbf{d p p}$ surface, enhancing their electrical connection, and physically stabilises PSII on the electrode ${ }^{4,37}$. The integration of all biotic and abiotic components in the hybrid photoanode was further confirmed by high angular annular dark field scanning transmission electron microscopy (HAADF-STEM) (Supplementary Fig. 5).

The UV-Vis absorption spectra of dpp, Pos and PSII in solution and individually adsorbed on $\mathrm{IO}^{-\mathrm{TiO}_{2}}$ electrodes were recorded (Fig. 1 and Supplementary Fig. 6). IO-TiO 2 PSII displays absorption maxima $\left(\lambda_{\max }\right)$ at $450 \mathrm{~nm}\left(\mathrm{~B}_{\mathrm{x} / \mathrm{y}}\right.$ Soret bands) and 680 $\mathrm{nm}\left(\mathrm{Q}_{\mathrm{y}} \text { band) }\right)^{38}$, whereas $1 \mathrm{O}-\mathrm{TiO}_{2} \mid \mathbf{d p p}$ showed a broad absorption from 475 to 575 $\mathrm{nm}$. Thus, the absorption spectra of the co-sensitised $\mathrm{IO}^{\mathrm{T}} \mathrm{TiO}_{2}$ electrode demonstrate panchromatic light absorption and highlight the light harvesters' complementarity desired for a semi-artificial Z-scheme. For comparison, the spectrum of RuP ( $\lambda_{\max }=$ $457 \mathrm{~nm}$ ) significantly overlaps with PSII $\left(\lambda_{\max }\right.$ of $\mathrm{B}_{\mathrm{x} / \mathrm{y}}$ band at $\left.450 \mathrm{~nm}\right)$. The $1 \mathrm{O}-\mathrm{TiO}_{2} \mid \mathrm{Pos}_{\text {s }}$ spectrum consisted of a broad and weak absorption, in line with the modest molar absorption of $P_{o s}\left(\varepsilon=8.72 \mathrm{mM}^{-1} \mathrm{~cm}^{-1} \text { at } 531 \mathrm{~nm}\right)^{4}$, which is not expected to 
substantially affect light conversion efficiency in the fully assembled IO$\mathrm{TiO}_{2}|\mathbf{d p p}| \mathbf{P}_{\text {os }}-\mathbf{P S I}$ tandem system.

\section{Photoelectrochemistry}

The photocurrent response $(J)$ of $I O-\mathrm{TiO}_{2}|\mathbf{d p p}| \mathrm{P}_{\mathrm{os}}-\mathrm{PSII}$ was recorded by PF-PEC at an applied potential $\left(E_{a p p}\right)$ in a three-electrode configuration. Stepped-potential chronoamperometry under periodic illumination with UV-filtered simulated solar light was used (1.5 AM filter; irradiance $E_{e}=100 \mathrm{~mW} \mathrm{~cm}{ }^{-2} ; \lambda>420 \mathrm{~nm}$, Fig. 2). Photogenerated electrons in PSII are transferred to the electron acceptor plastoquinone $B\left(Q_{B}\right)$ (Fig. 1)9. The holes are collected at the oxygen-evolving complex (OEC), where water is oxidised to liberate protons and gaseous $\mathrm{O}_{2}$. The conduction band $(\mathrm{CB})$ of $\mathrm{IO}-\mathrm{TiO}_{2}$ receives electrons from the photoexcited dpp which is thereby oxidised $\left(\mathbf{d p p}^{+}\right)$, giving rise to anodic photocurrent. The Os ${ }^{2+}$-complex embedded in Pos mediates the electrons between reduced $Q_{B}$ and oxidised $\mathbf{d p p}$ to close the electric circuit between the two light absorbers.

The photoanodic current onset potential $\left(E_{\text {onset }}\right)$ of approximately $-0.5 \mathrm{~V}$ vs. standard hydrogen electrode ( $\mathrm{SHE}$ ) is consistent with the reported anatase $\mathrm{TiO}_{2}$ conduction band (CB) edge of approximately -0.6 vs. SHE ${ }^{39}$ (Fig. 2; Supplementary Fig. 7). The $1 \mathrm{O}-\mathrm{TiO}_{2}|\mathbf{d p p}| \mathrm{Pos}_{\mathrm{s}}-\mathrm{PSI}$ tandem electrode exhibits a shift of more than $0.5 \mathrm{~V}$ towards negative potential compared to single-absorber photoanodes with immobilised PSII ${ }^{3,4,40}$, which makes it a promising candidate for bias-free overall water splitting. Potential independent steady-state photocurrents $\left(80 \mu \mathrm{A} \mathrm{cm}^{-2}\right)$ were observed at $E_{a p p}$ $>-0.2$ V vs. SHE (Fig. 2b) and attributed to water oxidation ${ }^{3,4}$. Prolonged irradiation at $E_{a p p}>-0.2 \mathrm{~V}$ vs. SHE results in an irreversible drop in photocurrent, most likely due to PSIl photodegradation (irreversible light-induced D1 subunit damage) ${ }^{4}$. 
Control experiments omitting one component of the tandem photoanode exhibited only a marginal photoactivity. The small background photoresponse for IO$\mathrm{TiO}_{2}|\mathbf{d p p}| \mathbf{P S I}$ and $\mathrm{IO}-\mathrm{TiO}_{2}|\mathbf{d p p}| \mathbf{P o s}$ (Fig. 2, and similar for $I \mathrm{O}-\mathrm{TiO}_{2} \mid \mathbf{d p p}$, Supplementary Fig. 7a,b) can be assigned to stoichiometric electron transfer from photoexcited $\mathbf{d p p}\left(\mathbf{d p p ^ { * } )}\right.$ to $\mathrm{TiO}_{2}$ without regeneration and photocatalytic turnover of the dye. Low photocurrent in the absence of $\mathrm{Pos}_{\mathrm{Os}}\left(\mathrm{IO}-\mathrm{TiO}_{2}|\mathbf{d p p}| \mathrm{PSII}\right)$ supports insufficient direct electronic interaction between PSII and dpp without the redox polymer ${ }^{4}$. No significant photocurrents were observed in the absence of dpp (IO$\mathrm{TiO}_{2} \mid \mathbf{P o s}_{\mathrm{os}}-\mathbf{P S I}$, Fig. 2, IO- $-\mathrm{TiO}_{2}, \quad \mathrm{IO}-\mathrm{TiO}_{2}\left|\mathbf{P o s}, \mathrm{IO}-\mathrm{TiO}_{2}\right|$ PSII, Supplementary Fig. 7a,b) consistent with the more positive reduction potentials of PSII's Qв and Pos relative to the $\mathrm{CB}$ of $\mathrm{TiO}_{2}$, resulting in unfavourable electron transfer. The presented semi-artificial system therefore demonstrates the successful assembly of a functional biotic-abiotic interface for controlled electron-transfer in an artificial Zscheme. A PSII tandem system based on $1 \mathrm{O}-\mathrm{TiO}_{2} \mid \mathbf{R u P}$ was also assembled and exhibited a similar behaviour (Supplementary Fig. 7c,d). To maximise the performance of the tandem systems, screening of dye loading (Supplementary Fig. 8), Pos/PSIl ratio (Supplementary Fig. 9) and $\mathrm{IO}^{-\mathrm{TiO}_{2}}$ thickness (Supplementary Fig. 10) was conducted.

\section{Photocurrent action spectrum}

The photocurrent response as a function of irradiation wavelength (the photocurrent action spectrum) was recorded for $1 \mathrm{O}-\mathrm{TiO}_{2} \mid$ dye $\mid \mathbf{P}_{\mathrm{os}}-\mathbf{P S I I}$ and relevant control samples (Fig. 3a) to characterise the complementary light absorption of the tandem photoanode (Supplementary Fig. 1). In a typical experiment, the wavelength was decreased from 760 to $420 \mathrm{~nm}\left(\lambda_{s c a n}\right)$ at $E_{a p p}=0.5 \mathrm{~V}$ vs. SHE whilst measuring the 
photocurrent. The action spectra were corrected to equal photon flux at each wavelength and normalised (Supplementary Figs. 11, 12).

In agreement with the photocurrent responses under full visible light irradiation (Fig.

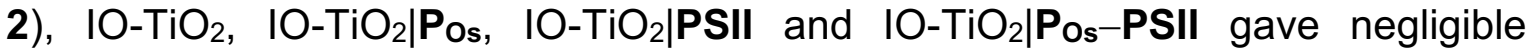
photocurrents upon monochromatic light illumination across all wavelengths (Fig. 3a). PSIl-free electrodes loaded with dpp $\left(\mathrm{IO}-\mathrm{TiO}_{2}|\mathbf{d p p},| \mathrm{O}-\mathrm{TiO}_{2}|\mathbf{d p p}| \mathrm{Pos}\right)$ gave small photocurrent responses concurrent with the absorption spectrum of dpp, consistent with the assignment of background current due to dpp photooxidation (see above). For the functional $\left|\mathrm{O}-\mathrm{TiO}_{2}\right| \mathbf{d p p} \mid \mathrm{Pos}_{\mathrm{os}}-\mathrm{PSIl}$ tandem system, the photocurrent onset was observed at $\lambda_{\text {scan }}=620 \mathrm{~nm}$, with a maximum photocurrent at approximately $560 \mathrm{~nm}$. This photoresponse is consistent with the spectral overlap of PSII with dpp and the required simultaneous excitation of both photoactive components $^{41}$. The absence of photocurrent at $\lambda_{\text {scan }}>620 \mathrm{~nm}$ is consistent with the requirement of dpp excitation for electron injection into the $\mathrm{CB}$ of $\mathrm{TiO}_{2}$ and $\mathrm{Pos}_{\mathrm{s}}$ oxidation. An external quantum efficiency $(E Q E)^{21}$ of $2.7 \%$ was obtained at $\lambda_{\max }=$ $560 \mathrm{~nm}\left(E_{e}=6 \mathrm{~mW} \mathrm{~cm}^{-2}\right)$.

Dual-wavelength action spectra were also recorded by coupling excitation by the scanned monochromatic light $\left(\lambda_{\text {scan }}\right)$ to simultaneous irradiation at a fixed wavelength to continuously excite either PSII ( $\lambda_{\text {const }}=660 \mathrm{~nm}$, Fig. $\mathbf{3 b}$ and Supplementary Fig. 12b) or dpp ( $\lambda_{\text {const }}=523$ nm, Supplementary Fig. 12c). Continuous excitation of PSII (thereby probing dpp) in IO-TiO $2|\mathbf{d p p}| \mathbf{P}_{\mathbf{O}}-\mathbf{P S I}$ (Fig. 3b) led to an action spectrum profile (with regard to $\lambda_{\text {scan }}$ ) similar to the UV-Vis spectrum of dpp and the single-wavelength excitation experiment. In comparison to the latter, a maximum at $\lambda_{\text {scan }}=550 \mathrm{~nm}$ was also observed, but with a $40 \%$ higher photocurrent magnitude. The overall photocurrent cross-section using dual- 
excitation (Fig. 3b) was approximately two times higher compared to cross-sections of individual components (Fig. 3a), confirming the functional and efficient dualabsorber tandem mechanism in the $\mathrm{IO}^{-\mathrm{TiO}_{2}}|\mathbf{d p p}| \mathrm{P}_{\mathrm{os}}-\mathrm{PSII}$ (Supplementary Fig. 1).

Continuous excitation of dpp (probing PSII) (Supplementary Fig. 12c) resulted in a general increase in photocurrent across all wavelengths (760 to $420 \mathrm{~nm}$ ) compared to the single-wavelength excitation action spectrum. A new photocurrent maximum was detected at $680 \mathrm{~nm}$, corresponding to the PSII $Q_{y}$ band. A photocurrent maximum at $550 \mathrm{~nm}$ remained, corresponding to higher intensity excitation of the PSII/dpp spectral overlap region, leading to higher photocurrent compared to the single-wavelength experiment. Absorption at $480 \mathrm{~nm}$, corresponding to excitation of the PSII $\beta$-carotene, and $\leq 420 \mathrm{~nm}$, corresponding to excitation of the $B_{x}$ and $B_{y}$ bands, were also observed. Action spectra of the RuPsensitised photoanodes recorded for comparison (Supplementary Fig. 13, 14) also correlated with the UV-Vis absorption spectrum of RuP (Supplementary Fig. 6) and exhibited analogous features.

\section{Bias-free overall water splitting via artificial Z-scheme}

The negative $E_{\text {onset }}$ and broad absorption spectrum of the $1 \mathrm{O}-\mathrm{TiO}_{2}|\mathbf{d p p}| \mathbf{P o s}_{\mathrm{s}}-\mathrm{PSI}$ tandem photoanode make it a suitable light absorber for bias-free (unassisted) overall water splitting. To achieve this long-standing goal ${ }^{16,42}$, the photoanode was wired to a previously reported indium tin oxide (ITO)-based IO-ITO| $\mathrm{H}_{2}$ ase cathode ${ }^{3}$, which utilises a reversible biological electrocatalyst for $\mathrm{H}_{2}$ production integrated in a hierarchically-structured ITO electrode. The Desulfomicrobium baculatum [NiFeSe]$\mathrm{H}_{2}$ ase was used for its high proton reduction activity, $\mathrm{O}_{2}$ tolerance under reductive conditions and marginal inhibition by $\mathrm{H}_{2}$, offering advantageous properties for water splitting compared to $\mathrm{O}_{2}$-sensitive $[\mathrm{FeFe}]-\mathrm{H}_{2}$ ases available in algal $\mathrm{H}_{2}$ production ${ }^{43}$. 
ITO has been shown to be a suitable electrode material for the wiring of [NiFeSe]$\mathrm{H}_{2}$ ases in a direct electron transfer regime, and the IO-ITO| $\mathrm{H}_{2}$ ase electrode exhibited high current densities for proton reduction $\left(>400 \mu \mathrm{A} \mathrm{cm}{ }^{-2}\right)$ and $E_{\text {onset }}$ of $-0.35 \mathrm{~V}$ vs. SHE ( $\mathrm{pH} 6.5 ; \mathrm{N}_{2}$ atmosphere $)^{3}$. Comparison of the voltammetric responses of IO$\mathrm{TiO}_{2}|\mathbf{d p p}| \mathbf{P}_{\mathbf{O}}-\mathbf{P S I}$ and IO-ITO| $\mathbf{H}_{2}$ ase measured individually (Supplementary Fig. $15)$ indicate that $E_{\text {onset }}$ of the anodic $(-0.50 \mathrm{~V}$ vs. SHE) and cathodic ( $-0.35 \mathrm{~V}$ vs. SHE) current responses overlap by approximately $0.15 \mathrm{~V}^{42,44}$. Thus, a two-electrode PEC cell consisting of the two enzyme-modified electrodes should be capable of bias-free solar-driven water splitting, assuming only minor resistive solution/membrane losses $^{45}$. Comparison of the current densities indicates that $1 \mathrm{O}-\mathrm{TiO}_{2}|\mathbf{d p p}| \mathbf{P o s}_{\mathbf{s}}-\mathbf{P S I I}$ should primarily limit the current response when wired to IO-ITO| $\mathrm{H}_{2}$ ase.

A semi-artificial PEC device was therefore assembled consisting of a IO$\mathrm{TiO}_{2}|\mathbf{d p p}| \mathbf{P}_{\mathbf{O}}-\mathbf{P S I I}$ photoanode connected to a IO-ITO| $\mathbf{H}_{2}$ ase cathode separated by a glass frit membrane in a two-electrode, two-compartment cell. Fig. 4 demonstrates the ability of the system to achieve bias-free solar-driven water splitting. Chronoamperometry measurements with longer irradiation times (Fig. 4a) were performed to minimise the charging effects below an applied voltage $\left(U_{a p p}\right)$ of $0 \mathrm{~V}$. At more positive voltages, the charging effects were decreased and photocurrent responses stabilised. Upon irradiation with UV-filtered simulated solar light, a current density of $28 \pm 5 \mu \mathrm{A} \mathrm{cm} \mathrm{cm}^{-2}$ was achieved at $U_{a p p}=0 \mathrm{~V}$ (Fig. 4b). Voltage independent steady-state photocurrents $\left(122 \pm 21 \mu \mathrm{A} \mathrm{cm}{ }^{-2}\right)$ were reached at $U_{a p p}=0.3 \mathrm{~V}$. The photocurrent magnitudes were similar to a two-electrode system with a Pt cathode instead of $\mathrm{IO}-\mathrm{ITO} \mid \mathrm{H}_{2}$ ase (Supplementary Fig. 16), consistent with photocurrent limitation by $1 \mathrm{O}-\mathrm{TiO}_{2}|\mathbf{d p p}| \mathrm{Pos}_{\mathbf{0}}-\mathrm{PSII}$. A two-electrode system with a $\mathrm{IO}-\mathrm{TiO}_{2} \mid \mathrm{H}_{2}$ ase 
cathode was also assembled and exhibited a similar behaviour, albeit with less charging due to the matched Fermi levels of $\mathrm{IO}^{-\mathrm{TiO}_{2}}$ (Supplementary Fig. 17).

Overall water splitting with the $1 \mathrm{O}-\mathrm{TiO}_{2}|\mathbf{d p p}| \mathbf{P o s}-\mathrm{PSII} \| \mathrm{IO}-\mathrm{ITO} \mid \mathrm{H}_{2}$ ase PEC cell was studied at $U_{a p p}=0.0$ and $0.3 \mathrm{~V}$ (Supplementary Figure 18a). At zero bias $\left(U_{a p p}=0\right.$ V), the initial photocurrent decayed from $130 \mu \mathrm{A} \mathrm{cm}^{-2}$ to $5 \mu \mathrm{A} \mathrm{cm}^{-2}$ after $1 \mathrm{~h}$ irradiation, leading to an average half-life time $\left(\tau_{1 / 2}\right)$ of $6.5 \mathrm{~min}$. At $U_{a p p}=0.3 \mathrm{~V}$, the photocurrent decayed from $140 \mu \mathrm{A} \mathrm{cm} \mathrm{cm}^{-2}$ to $15 \mu \mathrm{A} \mathrm{cm} \mathrm{cm}^{-2}$ after $1 \mathrm{~h}$ irradiation with a $\tau_{1 / 2}$ of $\sim 8 \mathrm{~min}$. These lifetimes are similar to previously reported PSII-based photoanodes ${ }^{3,4}$, and consistent with the stability of PSII in vivo $\left(\tau_{1 / 2} \text { of } \sim 20 \mathrm{~min}\right)^{9}$. The relative stability of the IO- $\mathrm{TiO}_{2}|\mathbf{d p p}| \mathbf{P o s}_{\mathbf{0}}-\mathbf{P S I}$ system can be attributed to the efficient electron transfer between $\mathrm{TiO}_{2}$ - $\mathbf{d p p}-\mathbf{P o s}_{\mathbf{s}}-\mathbf{P S I}$, physical stabilisation of PSIl by the polymer and reduced accumulation of excited states in Chl a within PSII ${ }^{46}$. However, it is important to emphasise that the current hybrid enzyme system is a proof-of-concept device, and its practical applicability is intrinsically limited by the photodegradation pathways of PSIl in vitro.

After $1 \mathrm{~h}$ of continuous light irradiation at $U_{\text {app }}=0.0 \mathrm{~V}, \mathrm{H}_{2}$ was detected $(0.06 \mu \mathrm{mol} \mathrm{H}$ $\mathrm{cm}^{-2}$ ) with a Faradaic efficiency $\left(\eta_{F}\right)$ of $76 \%$, but reliable $\mathrm{O}_{2}$ analysis was prevented by the detection limit of the apparatus. At $U_{a p p}=0.3 \mathrm{~V}, \mathrm{O}_{2}$ and $\mathrm{H}_{2}$ were quantified (Fig. 4b, inset) with $\eta_{F}$ of $88 \pm 12 \%$ and $82 \pm 10 \%$, respectively (Supplementary Table 1) and a STH conversion efficiency of $0.14 \pm 0.02 \%$ was obtained ${ }^{47}$. A PSIl-based TOF of $2.5 \pm 0.3 \mathrm{~mol} \mathrm{O}_{2}(\mathrm{~mol} \text { PSII })^{-1} \mathrm{~s}^{-1}$ was calculated based on quantified $\mathrm{O}_{2}$ and $\mathrm{PSII}^{3,4}$. Previously, similar $\eta_{F}$ values were reported for benchmark PSII-photoanodes: diffusional-mediated IO-ITO|PSII ${ }^{3}$ and IO-ITO|Pos-PSII ${ }^{4}$, but required significantly higher driving force $\left(U_{a p p}=0.9 \mathrm{~V}\right.$ and $E_{a p p}=0.5 \mathrm{~V}$ vs. SHE, respectively $)$. Negligible photocurrents were detected in control experiments (Supplementary Fig. 18b; 
Supplementary Table 1). $\mathrm{O}_{2}$ evolution was also confirmed using a rotating ring-disc electrode (RRDE) setup (Supplementary Fig. 19).

\section{Conclusions}

The reported enzyme-based tandem PEC system consisting of an IO$\mathrm{TiO}_{2}|\mathbf{d p p}| \mathrm{Pos}_{\mathbf{s}}-\mathrm{PSI}$ photoanode connected to a IO-ITO| $\mathbf{H}_{2}$ ase cathode achieves the long-standing goal of a bias-free in vitro system for overall water splitting using PSII ( $\mathrm{O}_{2}$ generation) connected to $\mathrm{H}_{2}$ ase $\left(\mathrm{H}_{2}\right.$ generation). This semi-artificial design addresses key limitations in biology as PEC wiring of PSII to $\mathbf{H}_{2}$ ase via an abiotic dye allows for: panchromatic solar light absorption by using a synthetic green-light absorber (in contrast to non-complementary absorption by PSI); quantitative use of electrons extracted from PSIl for $\mathrm{H}_{2}$ production (and thereby avoiding inefficient metabolic pathways); and separation of $\mathrm{H}_{2}$ and $\mathrm{O}_{2}$ gas in separate compartments (as opposed to inhibiting an $\mathrm{O}_{2}$-sensitive $\mathrm{H}_{2}$ ase).

The tandem system produced $\mathrm{H}_{2}$ and $\mathrm{O}_{2}$ from water with high Faradaic efficiencies in 2:1 ratio and presents an effective strategy for constructing biotic-abiotic interfaces. Future work will involve investigating other dyes and replacing $\mathrm{TiO}_{2}$ with a semiconductor with a more negative CB potential to enhance driving force for more efficient catalysis or $\mathrm{CO}_{2}$ reduction chemistry. Moreover, our study provides a blueprint for advancing future semi-artificial systems capable of bias-free photocatalysis and a toolbox for developing proof-of-concept model systems for solar energy conversion. 


\section{Materials and Methods}

\section{Materials}

All chemicals: 2-(N-morpholino)ethane sulfonic acid (MES, Alfa Aesar), tetrabutylammonium hydroxide (TBAOH, Sigma Aldrich), $\mathrm{CaCl}_{2}$ (Breckland Scientific), $\mathrm{MgCl}_{2}$ (Fisher Scientific), $\mathrm{KCl}$ (Alfa Aesar), $\mathrm{KOH}$ (Breckland Scientific), polystyrene (PS) beads (Polysciences Inc., $750 \mathrm{~nm}$ diameter, $2.6 \% \mathrm{w} / \mathrm{v}$ suspension in $\mathrm{H}_{2} \mathrm{O}$ ), titanium dioxide $\left(\mathrm{TiO}_{2}\right.$ ) nanoparticles (NPs) (Evonik Industries, Aeroxide ${ }^{\circledR} \mathrm{P} 25 \mathrm{TiO}_{2}$ nanoparticles; $21 \mathrm{~nm}$ diameter; 80/20 anatase/rutile w/w), indium tin oxide (ITO) NPs (Sigma Aldrich; <50 nm diameter), fluorine-doped tin oxide (FTO) coated glass slides (8 $\Omega$ sq $^{-1}$; Sigma Aldrich) and Parafilm $^{\circledR}$ (Sigma Aldrich) were purchased from commercial suppliers and used without further purification unless otherwise noted. Methanol, absolute ethanol, 2-propanol, dimethyl sulfoxide, tetrahydrofuran (HPLC grade) were purchased from Sigma Aldrich. PSII was isolated from the thermophilic cyanobacterium Thermosynechococcus elongatus according to a previously reported procedure ${ }^{35}$, with an average oxygen-evolving activity of approximately $5,300 \mu \mathrm{mol} \mathrm{O}_{2}$ $\mathrm{h}^{-1} \mathrm{mg}^{-1}$ of chlorophyll a (Chl a). A stock PSIl solution containing $2.6 \mathrm{mg} \mathrm{Chl} \mathrm{a} \mathrm{mL}^{-1}$ (83 $\mu \mathrm{M}$ PSII) was stored in a liquid $\mathrm{N}_{2}$ Dewar. [NiFeSe]- $\mathrm{H}_{2}$ ase from Desulfomicrobium baculatum was purified using a previously published method ${ }^{48}$, with a specific activity of 2,115 $\mu \mathrm{mol} \mathrm{H} \mathrm{H}_{2} \mathrm{~min}^{-1} \mathrm{mg}^{-1}$. Stock solutions of $\mathrm{H}_{2}$ ase $(8 \mu \mathrm{M}$, in $20 \mathrm{mM}$ Tris/HCl buffer, $\mathrm{pH} 7.0$ ) were stored in $10-20 \mu \mathrm{L}$ aliquots at $-40{ }^{\circ} \mathrm{C}$ in an anaerobic glovebox and used immediately after thawing.

\section{Polymer and dye synthesis}

Poly(1-vinylimidazole-co-allylamine)-Os(bipy) ${ }_{2} \mathrm{Cl}\left(\mathbf{P o s}_{\text {os }}\right)^{37}$ was synthesised according to previously reported procedures ${ }^{4}$. In brief, an ethanolic solution of cis-[OSCl$\left.{ }_{2}(\text { bipy })_{2}\right]$ and poly(1-vinylimidazole-co-allylamine) backbone (1/1.65 weight ratio) was stirred for 
5 days at $90{ }^{\circ} \mathrm{C}$. Pos was then precipitated by addition of diethyl ether, collected by centrifugation and dried under vacuum to obtain a reddish powder. An aqueous solution of Pos $\left(10 \mathrm{mg} \mathrm{mL}^{-1}\right)$ was used in all experiments. The diketopyrrolopyrrolebased dye (dpp) was synthesised using a previously reported procedure ${ }^{27}$. Briefly, pseudo-Stobbe condensation of 1-bromo-4-cyanobenzene with diethyl succinate was followed by lactam $\mathrm{N}$-alkylation then desymmetrisation of the intermediate via SuzukiMiyaura cross-coupling. The phosphonic acid anchoring group was then added via Hirao cross-coupling using diethyl phosphite followed by hydrolysis. To obtain ruthenium bis(2,2'-bipy)(4,4'-bis(phosphonic acid)-2,2'-bipy) dibromide (RuP), $\mathrm{Me}_{3} \mathrm{SiBr}$ was added to a solution of $\left[\mathrm{Ru}(\text { bipy })_{2}\left(4,4^{4}-\left(\mathrm{PO}_{3} \mathrm{Et}_{2}\right)_{2}\right.\right.$ bipy $\left.)\right]\left(\mathrm{PF}_{6}\right)_{2}$ in dry dimethylformamide and the mixture was heated in the dark at $60^{\circ} \mathrm{C}$ for $18 \mathrm{~h}$ under $\mathrm{Ar}$ then concentrated under vacuum. Methanol was added and the solution was stirred at room temperature for $3 \mathrm{~h}$. The product was precipitated by adding diethyl ether and dried under vacuum to afford $\left[\mathrm{Ru}(\text { bipy })_{2}\left(4,4^{4}-\left(\mathrm{PO}_{3} \mathrm{H}_{2}\right)_{2}\right.\right.$ bipy $\left.)\right](\mathrm{Br})_{2}(\mathrm{RuP})^{29}$. Both dpp and RuP were characterised as previously reported.

\section{Instrumentation}

The surface morphology of the electrodes was analysed by scanning electron microscopy (SEM; Philips SFEG XL30; acceleration voltage 5 kV; WD 5 mm), energy dispersive X-ray (EDX) spectroscopy attached to the SEM, scanning transmission electron microscopy (STEM; TitanX 60-300 with High Angle Annular Dark Field (HAADF) detector; acceleration voltage $300 \mathrm{kV}$ ) and powder X-Ray diffraction (PXRD; PANalytics Empyrean 2). A centrifuge (5804 Eppendorf), furnace (Carbolite, ELF 11/14B/301) and UV/Ozone cleaner (ProCleaner Plus, BioForce Nanosciences) were used for electrode preparation. UV-vis absorption spectra were recorded on an FS5 spectrofluorometer (Edinburgh Instruments; integrating sphere reflectance mode) and 
spectrophotometer (Varian Cary 50, Agilent), using cuvettes with an optical path length of $1 \mathrm{~cm}$ (transmittance mode). With the integrating sphere, the measurement was performed by concentrating the light reflected from the electrode on the detector using a polytetrafluoroethylene-coated sphere $(120 \mathrm{~mm}$ in diameter). The relative reflectance was measured with respect to the reflectance of the reference standard white board, which is taken to be $100 \%$.

\section{Preparation of $\mathrm{IO}_{-} \mathrm{TiO}_{2}$ electrodes}

The $1 \mathrm{O}-\mathrm{TiO}_{2}$ electrodes were fabricated according to a method adopted from a previously reported procedure for the synthesis of IO-ITO ${ }^{3,4}$. FTO-coated glass slides $\left(2 \times 1 \mathrm{~cm}^{2}\right)$ were cleaned by sonication in two 30 min steps in 2-propanol and absolute ethanol. First, to ensure no direct contact of the electroactive components (PSIl and Pos) with the FTO layer, it was coated with a layer of mesoporous $\mathrm{TiO}_{2}($ mesoTiO 2$)$. $\mathrm{TiO}_{2}$ NPs (50 mg) were dispersed via sonication for 20 min in a $\mathrm{MeOH} /$ water mixture $(300 \mu \mathrm{L}, 5: 1 \mathrm{v} / \mathrm{v})$. The suspension $(10 \mu \mathrm{L})$ was deposited onto a $0.50 \mathrm{~cm}^{2}$ area defined by a Parafilm $®$ ring on an FTO slide and doctor bladed to give a $3 \mu \mathrm{m}$ thick meso $\mathrm{TiO}_{2}$ layer. The $\mathrm{IO}-\mathrm{TiO}_{2}$ layer was then deposited on top of the mesoTiO 2 layer. $\mathrm{TiO}_{2} \mathrm{NPs}$ (30 mg) were dispersed in a water/MeOH mixture $(300 \mu \mathrm{L}, 4: 1 \mathrm{v} / \mathrm{v})$ via sonication (3 h). The PS bead dispersion (1 mL) was centrifuged $(10,000 \mathrm{rpm}, 3 \mathrm{~min})$, and the supernatant was removed. The pellet was redispersed in $\mathrm{MeOH}(1 \mathrm{~mL})$ before being centrifuged again $(10,000 \mathrm{rpm}, 0.5 \mathrm{~min})$. The supernatant was removed and the $\mathrm{TiO}_{2}$ NPs dispersion was added to the PS pellet. The pellet was dispersed into the solution by sonication $\left(10 \mathrm{~min},<10^{\circ} \mathrm{C}\right)$. The resulting $\mathrm{PS}^{-\mathrm{TiO}_{2}} \mathrm{NPs}$ dispersion was drop-cast $(5 \mu \mathrm{L})$ onto a $0.25 \mathrm{~cm}^{2}$ area defined by a Parafilm ring on an FTO slide. Following evaporation of the solvent, the electrodes were annealed at a $1{ }^{\circ} \mathrm{C} \min ^{-1}$ ramp rate from room temperature to $500{ }^{\circ} \mathrm{C}$ and sintered for 20 min giving a $20 \mu \mathrm{m}$ thick $\mathrm{IO}-\mathrm{TiO}_{2}$ film. The electrodes were allowed to cool to room temperature and cleaned with an 
UV/ozone cleaner (15 min) and characterised by SEM and HAADF-STEM, elemental mapping using EDX, and powder XRD (Supplementary Fig. 2).

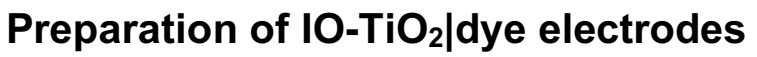

$\mathrm{IO}-\mathrm{TiO}_{2}$ electrodes with a pore diameter of $750 \mathrm{~nm}, 20 \mu \mathrm{m}$ film thickness and a geometrical surface area of $0.25 \mathrm{~cm}^{2}$ were used in all experiments, unless stated otherwise. The $1 \mathrm{O}-\mathrm{TiO}_{2} \mid$ dye modified electrodes were prepared by soaking $\mathrm{IO}-\mathrm{TiO}_{2}$ electrodes in solutions of dpp or RuP $\left(0.15 \mathrm{mM}\right.$ in $\mathrm{THF} / \mathrm{H}_{2} \mathrm{O}$, respectively) overnight in the dark. To remove excess dye prior to enzyme/polmer deposition, the $1 \mathrm{O}-\mathrm{TiO}_{2} \mid \mathbf{d p p}$ electrodes were rinsed with THF, followed by water, then air-dried. Similarly, the IO$\mathrm{TiO}_{2} \mid \mathbf{R u P}$ electrodes were rinsed with water and air-dried.

\section{Preparation of $1 \mathrm{OO}-\mathrm{TiO}_{2}|\mathrm{dye}| \mathrm{Pos}_{\mathrm{O}}-\mathrm{PSI}$ electrodes}

The IO-TiO 2 dye|Pos-PSII electrodes were prepared by depositing a blend of PSII (1 $\left.\mu \mathrm{L}, 2.6 \mathrm{mg} \mathrm{Chl} \mathrm{a} \mathrm{mL}^{-1}\right)$ stock solution and $\mathrm{Pos}_{\mathrm{os}}\left(1 \mu \mathrm{L}, 10 \mathrm{mg} \mathrm{mL}^{-1}\right)$ onto the $\mathrm{IO}-\mathrm{TiO}_{2}$ dye electrode (20 $\mu \mathrm{m}$ thick) and incubating the electrodes in the dark for $15 \mathrm{~min}$ at room temperature. Prior to electrochemical studies, the $1 \mathrm{O}-\mathrm{TiO}_{2} \mid$ dye $\mid \mathbf{P o s}_{\mathbf{o s}}-\mathbf{P S I I}$ electrode was rinsed $(3 \times 500 \mu \mathrm{L})$ with the PSII buffer electrolyte solution (composition given below) to remove loosely bound species from the electrode surface.

\section{Determination of PSII, Pos and dye loading on $\mathrm{IO}_{\mathrm{O}} \mathrm{TiO}_{2}$}

The amount of PSII on the $\mathrm{IO}^{-\mathrm{TiO}_{2}}$ surface was quantified by scratching off the IO$\mathrm{TiO}_{2}$ from the FTO glass substrate and washing it with $\mathrm{MeOH}(500 \mu \mathrm{L})$ to extract $\mathrm{Chl}$ a (originating from PSII) from the electrode surface into a centrifuge vial. The vial was centrifuged $(10,000 \mathrm{rpm}, 1 \mathrm{~min})$, and the UV-vis spectrum of the supernatant was recorded (Supplementary Fig. 4b). The band with an absorption maximum of $\lambda_{\max }=$ $665 \mathrm{~nm}$ assigned to $\mathrm{Chl}$ a (extinction coefficient $\varepsilon=79.95\left(\mathrm{Chl} \text { a mg) }{ }^{-1} \mathrm{~mL} \mathrm{~cm}^{-1}\right)^{49}$ 
was used to calculate the amount of PSII monomers ${ }^{49}$ assuming $35 \mathrm{Chl}$ a molecules per PSII monomer ${ }^{33}$. The Os-complex loading in the Pos was determined by ICP-OES obtained by washing off the $\mathrm{Pos}$ from the $\mathrm{IO}-\mathrm{TiO}_{2}$ electrode with aqueous concentrated $\mathrm{HNO}_{3}$ solution $(70 \% \mathrm{wt})$ and measuring the concentration of the $\mathrm{Os}^{2+}$ metal ions relative to Os ICP standard (1 $\mathrm{mg} \mathrm{Os} \mathrm{mL}^{-1}$ in $20 \% \mathrm{HCl}$, Ricca Chemical). The dpp/RuP loadings were quantified by scratching off the $1 \mathrm{O}-\mathrm{TiO}_{2} \mid$ dye from the glass substrate and washing with $\mathrm{TBAOH}(0.1 \mathrm{M})$ in $\mathrm{MeOH}(500 \mu \mathrm{L})$ to extract the dye from the electrode surface into a centrifuge vial. The vial was centrifuged $(10,000 \mathrm{rpm}, 1 \mathrm{~min})$ and the UV-vis spectrum of the supernatant was recorded (Supplementary Fig. 4a). The amount of dye desorbed into solution was estimated using the Beer-Lambert Law (Supplementary Fig. 4c,d).

\section{Preparation of IO-ITO| $\mathrm{H}_{2}$ ase electrodes}

[NiFeSe]- $\mathrm{H}_{2}$ ase was immobilised on ozone cleaned IO-ITO electrodes $(20 \mu \mathrm{m}$ film thickness, geometrical surface area, $A=0.25 \mathrm{~cm}^{2}$ ) by depositing the enzyme solution $(5 \mu \mathrm{L})$ on the electrode surface, followed by incubation for approximately $5 \mathrm{~min}$. The loading of [NiFeSe]- $\mathrm{H}_{2}$ ase (40 pmol) was adjusted to the electrode thickness, as reported previously ${ }^{3}$.

\section{Protein film photoelectrochemistry (PF-PEC) measurements}

Chronoamperometry and cyclic voltammetry (CV) measurements were performed using an Ivium Compactstat potentiostat and a gas-tight two-compartment glass cell with a water jacket for temperature control $\left(T=25^{\circ} \mathrm{C}\right)$. A three-electrode setup was employed with an $\mathrm{IO}-\mathrm{TiO}_{2}$ (or IO-ITO) working electrode, a $\mathrm{Ag} / \mathrm{AgCl}(3 \mathrm{M} \mathrm{KCl}$ ) reference electrode and a Pt wire counter electrode separated by a glass frit in another compartment. The cell was filled with a PSII electrolyte solution (12 mL, $\mathrm{pH} 6.5$ ) consisting of $\mathrm{CaCl}_{2}(20 \mathrm{mM}), \mathrm{MgCl}_{2}(15 \mathrm{mM}), \mathrm{KCl}(50 \mathrm{mM})$. All current densities $(\mu \mathrm{A}$ 
$\mathrm{cm}^{-2}$ ) are reported with respect to the geometrical surface area of the electrodes. Experimentally measured potentials are reported vs. SHE using the conversion $E_{S H E}$ $=E_{A g / A g C l}+0.197 \mathrm{~V}\left(25^{\circ} \mathrm{C}\right)$

Bias-free PEC overall water splitting and $\mathrm{O}_{2}$ and $\mathrm{H}_{2}$ quantification was studied using a two-electrode configuration with an $\mathrm{IO}^{-} \mathrm{TiO}_{2}$ photoanode containing PSII and an IOITO| $\mathrm{H}_{2}$ ase cathode. In all experiments involving IO-ITO| $\mathrm{H}_{2}$ ase cathode, MES (40 mM) was added to the PSII electrolyte solution as it was found to retain $\mathbf{H}_{2}$ ase electroactivity and only caused negligible photocurrents from MES oxidation.

PEC experiments were performed using a Xe lamp (150 W, Newport) Solar Light Simulator (LOT Quantum Design, light intensity flux (irradiance) $\left(E_{e}\right) 100 \mathrm{~mW} \mathrm{~cm}{ }^{-2}$, AM 1.5G filter, $\lambda>420 \mathrm{~nm}$ filter). Action spectra were recorded with a Xe lamp (300 W, Newport) Solar Light Simulator (LOT Quantum Design) coupled to a monochromator (MSH300, LOT Quantum Design). For dual excitation experiments, an Ivium modulight LED module $\left(\lambda=460 / 523 / 660 \mathrm{~nm} ; 4 \mathrm{~mW} \mathrm{~cm}^{-2}\right)$ was used as a second light source. Light intensity was measured as a function of wavelength with a thermal sensor (S302C, Thorlabs) and power meter console (PM100D, Thorlabs)

$1 \mathrm{O}-\mathrm{TiO}_{2} \mid$ dye $\mid \mathrm{Pos}_{\mathrm{os}}-\mathrm{PSI}$ electrodes were exposed to dark and light cycles in the PF-PEC measurements. The photocurrent response was defined as the baseline-corrected (dark current-subtracted) photocurrent peak shoulder edge after a light exposure, to avoid overestimation of photocurrent ${ }^{9}$. Action spectra were corrected to equal photon flux at each wavelength and normalised (taking the peak at $500 \mathrm{~nm}$ as unity). Error bars are \pm sample standard deviation estimated from at least three experiments. All data processing was performed using OriginPro 9.1 software. 
RRDE experiments were performed using $\mathrm{Ag} / \mathrm{AgCl}(3 \mathrm{M} \mathrm{KCl})$ reference and glassy carbon counter electrodes. The disk/ring apparatus was embedded in a cylindrical polyether ether ketone housing. A Pt ring electrode surrounded a glassy carbon disk electrode on which a mesoporous $\mathrm{TiO}_{2}$ layer was deposited prior to depositing additional components (dpp, Pos, PSII). The electrodes were placed in a singlecompartment cell under continuous purging with $\mathrm{N}_{2}$. The ring-disk electrode was rotated at $400 \mathrm{rpm}$ for $\mathrm{O}_{2}$ evolution measurements and the collection efficiency of the ring electrode was calibrated under conditions similar to those of the experiment (Supplementary Fig. 19).

\section{Product analysis}

Quantification of $\mathrm{O}_{2}$ was performed using a fluorescence-based $\mathrm{O}_{2}$ sensor (Neofox; Ocean Optics FOSFOR-R probe) inside an anaerobic glovebox (Belle Technology) to avoid ingress of atmospheric $\mathrm{O}_{2}$. The probe was placed inside the anodic compartment headspace of a two-compartment cell, protected from direct irradiation. The results are reported as the average of six measurements and the background signal was subtracted from all measurements. The reported $\mathrm{O}_{2}$ values were corrected for dissolved $\mathrm{O}_{2}$ using Henry's Law $\left(K_{H}\left(\mathrm{O}_{2}\right)=769.23 \mathrm{~L} \mathrm{~atm} \mathrm{~mol}^{-1}\right.$ at $\left.25^{\circ} \mathrm{C}\right) . \mathrm{H}_{2}$ was analysed by taking aliquots of the headspace gas $(50 \mu \mathrm{L})$ after electrolysis and quantified using gas chromatography (GC; Agilent 7890, carrier gas $\mathrm{N}_{2}$, flow rate 0.7 $\mathrm{mL} \mathrm{min}^{-1}$, molecular sieve column, thermal conductivity detector). Calibration runs were performed to quantify the volume of $\mathrm{H}_{2}$ evolved. The reported Faradaic efficiencies were corrected by subtracting the dpp dye background current estimated from control experiments from the experimental data. 


\section{Data availability}

The data that support the presented plots within this paper and other findings of this study are available at the University of Cambridge data repository with the identifier https://doi.org/xxxxx. 


\section{References}

1. Sakimoto, K. K., Wong, A. B. \& Yang, P. Self-photosensitization of nonphotosynthetic bacteria for solar-to-chemical production. Science 351, 74-77 (2016).

2. Yehezkeli, O. et al. Integrated photosystem II-based photo-bioelectrochemical cells. Nat. Commun. 3, 742-747 (2012).

3. Mersch, D. et al. Wiring of Photosystem II to Hydrogenase for Photoelectrochemical Watersplitting. J. Am. Chem. Soc. 137, 8541-8549 (2015).

4. Sokol, K. P. et al. Rational wiring of photosystem II to hierarchical indium tin oxide electrodes using redox polymers. Energy Environ. Sci. 9, 3698-3709 (2016).

5. Ort, D. R. et al. Redesigning photosynthesis to sustainably meet global food and bioenergy demand. Proc. Natl. Acad. Sci. 112, 8529-8536 (2015).

6. Tachibana, Y., Vayssieres, L. \& Durrant, J. R. Artificial photosynthesis for solar water-splitting. Nat. Photonics 6, 511-518 (2012).

7. Woolerton, T. W., Sheard, S., Chaudhary, Y. S. \& Armstrong, F. A. Enzymes and bio-inspired electrocatalysts in solar fuel devices. Energy Environ. Sci. 5, 7470-7490 (2012).

8. Léger, C. \& Bertrand, P. Direct Electrochemistry of Redox Enzymes as a Tool for Mechanistic Studies Direct Electrochemistry of Redox Enzymes as a Tool for Mechanistic Studies. Chem. Rev. 108, 2379-2438 (2008).

9. Kato, M., Zhang, J. Z., Paul, N. \& Reisner, E. Protein film photoelectrochemistry of the water oxidation enzyme photosystem II. Chem. Soc. Rev. 43, 6485-6497 (2014).

10. Bard, A. J. \& Fox, M. A. Artificial Photosynthesis: Solar Splitting of Water to Hydrogen and Oxygen. Acc. Chem. Res. 28, 141-145 (1995).

11. Govindjee, Shevela, D. \& Björn, L. O. Evolution of the Z-scheme of photosynthesis: a perspective. Photosynth. Res. 133, 5-15 (2017).

12. Barber, J. \& Tran, P. D. From natural to artificial photosynthesis. J. R. Soc. Interface 10, 1-16 (2013). 
13. Khetkorn, W. et al. Microalgal hydrogen production - A review. Bioresour. Technol. 243, 1194-1206 (2017).

14. Kruse, O., Rupprecht, J., Mussgnug, J. H., Dismukes, G. C. \& Hankamer, B. Photosynthesis: a blueprint for solar energy capture and biohydrogen production technologies. Photochem. Photobiol. Sci. 4, 957-969 (2005).

15. Michel, H. The nonsense of biofuels. Angew. Chem. Int. Ed. 51, 2516-2518 (2012).

16. Esper, B., Badura, A. \& Rögner, M. Photosynthesis as a power supply for (bio-)hydrogen production. Trends Plant Sci. 11, 543-549 (2006).

17. Hu, S., Xiang, C., Haussener, S., Berger, A. D. \& Lewis, N. S. An analysis of the optimal band gaps of light absorbers in integrated tandem photoelectrochemical water-splitting systems. Energy Environ. Sci. 6, 2984 (2013).

18. Kothe, T. et al. Combination of A Photosystem 1-Based Photocathode and a Photosystem 2Based Photoanode to a Z-Scheme Mimic for Biophotovoltaic Applications. Angew. Chem. Int. Ed. 52, 14233-14236 (2013).

19. Hartmann, V. et al. Redox hydrogels with adjusted redox potential for improved efficiency in Zscheme inspired biophotovoltaic cells. Phys. Chem. Chem. Phys. 16, 11936-11941 (2014).

20. Kim, Y. et al. Hybrid Z-Scheme Using Photosystem I and $\mathrm{BiVO}_{4}$ for Hydrogen Production. Adv. Funct. Mater. 25, 2369-2377 (2015).

21. Rao, K. K. et al. Photoelectrochemical responses of photosystem II particles immobilized on dye-derivatized $\mathrm{TiO}_{2}$ films. J. Photochem. Photobiol. B 5, 379-389 (1990).

22. Wang, W. et al. Spatially Separated Photosystem II and a Silicon Photoelectrochemical Cell for Overall Water Splitting: A Natural-Artificial Photosynthetic Hybrid. Angew. Chem. Int. Ed. 8530, 9229-9233 (2016).

23. Pinhassi, R. I. et al. Hybrid bio-photo-electro-chemical cells for solar water splitting. Nat. Commun. 7, 1-10 (2016).

24. O’Regan, B. \& Grätzel, M. A low-cost, high-efficiency solar cell based on dye-sensitised colloidal $\mathrm{TiO}_{2}$ films. Nature 353, 737-740 (1991). 
25. Xu, P., McCool, N. S. \& Mallouk, T. E. Water splitting dye-sensitized solar cells. Nano Today $14,42-58(2017)$.

26. Warnan, J. et al. A compact diketopyrrolopyrrole dye as efficient sensitizer in titanium dioxide dye-sensitized solar cells. J. Photochem. Photobiol. A Chem. 226, 9-15 (2011).

27. Warnan, J. et al. Solar $\mathrm{H}_{2}$ evolution in water with modified diketopyrrolopyrrole dyes immobilised on molecular Co and Ni catalyst-TiO 2 hybrids. Chem. Sci. 8, 3070-3079 (2017).

28. Muresan, N. M., Willkomm, J., Mersch, D., Vaynzof, Y. \& Reisner, E. Immobilization of a molecular cobaloxime catalyst for hydrogen evolution on a mesoporous metal oxide electrode. Angew. Chem. Int. Ed. 51, 12749-12753 (2012).

29. Lakadamyali, F., Reynal, A., Kato, M., Durrant, J. R. \& Reisner, E. Electron Transfer in DyeSensitised Semiconductors Modified with Molecular Cobalt Catalysts : Photoreduction of Aqueous Protons. Chem. Eur. J. 2, 15464-15475 (2012).

30. Knauf, R. R., Brennaman, M. K., Alibabaei, L., Norris, M. R. \& Dempsey, J. L. Revealing the Relationship between Semiconductor Electronic Structure and Electron Transfer Dynamics at Metal Oxide-Chromophore Interfaces. J. Phys. Chem. C 117, 25259-25268 (2013).

31. Li, F. et al. Immobilizing Ru(bda) Catalyst on a Photoanode via Electrochemical Polymerization for Light-Driven Water Splitting. ACS Catal. 5, 3786-3790 (2015).

32. Willkomm, J. et al. Dye-sensitised semiconductors modified with molecular catalysts for lightdriven $\mathrm{H}_{2}$ production. Chem. Soc. Rev. 45, 9-23 (2016).

33. Umena, Y., Kawakami, K., Shen, J.-R. \& Kamiya, N. Crystal structure of oxygen-evolving photosystem II at a resolution of $1.9 \AA$. Nature 473, 55-60 (2011).

34. Rapatskiy, L. et al. Detection of the Water-Binding Sites of the Oxygen-Evolving Complex of Photosystem II Using W-Band ${ }^{17} \mathrm{O}$ Electron-Electron Double Resonance-Detected NMR Spectroscopy. J. Am. Chem. Soc. 134, 16619-16634 (2012).

35. Kuhl, H. et al. Towards structural determination of the water-splitting enzyme: Purification, crystallization, and preliminary crystallographic studies of photosystem II from a thermophilic cyanobacterium. J. Biol. Chem. 275, 20652-20659 (2000). 
36. Kern, J. et al. Purification, characterisation and crystallisation of photosystem II from Thermosynechococcus elongatus cultivated in a new type of photobioreactor. Biochim. Biophys. Acta - Bioenerg. 1706, 147-157 (2005).

37. Badura, A. et al. Photo-induced electron transfer between photosystem 2 via cross-linked redox hydrogels. Electroanalysis 20, 1043-1047 (2008).

38. Senge, M. O., Ryan, A. A., Letchford, K. A., MacGowan, S. A. \& Mielke, T. Chlorophylls, symmetry, chirality, and photosynthesis. Symmetry. 6, 781-843 (2014).

39. Beranek, R. (Photo)electrochemical methods for the determination of the band edge positions of $\mathrm{TiO}_{2}$-based nanomaterials. Adv. Phys. Chem. 2011, 80-83 (2011).

40. Zhang, J. Z. et al. Competing charge transfer pathways at the photosystem II-electrode interface. Nat. Chem. Biol. 12, 1046-1052 (2016).

41. Razeghifard, R. \& Wydrzynski, T. J. Artificial Photosynthesis: From Basic Biology to Industrial Application. (John Wiley \& Sons, 2007).

42. Reisner, E., Powell, D. J., Cavazza, C., Fontecilla-Camps, J. C. \& Armstrong, F. A. Visible Light-Driven $\mathrm{H}_{2}$ Production by Hydrogenases Attached to Dye-Sensitized $\mathrm{TiO}_{2}$ Nanoparticles. J. Am. Chem. Soc. 131, 18457-18466 (2009).

43. Wombwell, C., Caputo, C. A. \& Reisner, E. [NiFeSe]-Hydrogenase Chemistry. Acc. Chem. Res. 48, 2858-2865 (2015).

44. Hambourger, M. et al. [FeFe]-hydrogenase-catalyzed $\mathrm{H}_{2}$ production in a photoelectrochemical biofuel cell. J. Am. Chem. Soc. 130, 2015-2022 (2008).

45. Coridan, R. H. et al. Methods for comparing the performance of energy-conversion systems for use in solar fuels and solar electricity generation. Energy Environ. Sci. 8, 2886-2901 (2015).

46. Cai, P. et al. Co-assembly of photosystem II/reduced graphene oxide multilayered biohybrid films for enhanced photocurrent. Nanoscale 7, 10908-10911 (2015).

47. Dotan, H., Mathews, N., Hisatomi, T., Grätzel, M. \& Rothschild, A. On the solar to hydrogen conversion efficiency of photoelectrodes for water splitting. J. Phys. Chem. Lett. 5, 3330-3334 (2014). 
48. Hatchikian, E. C., Bruschi, M. \& Le Gall, J. Characterisation of the Periplasmic Hydrogenase from Desulfovibrio Gigas. Biochem. Biophys. Res. Commun. 82, 451-461 (1978).

49. Porra, R. J., Thompson, W. A. \& Kriedemann, P. E. Determination of accurate extinction coefficients and simultaneous equations for assaying chlorophylls $a$ and $b$ extracted with four different solvents: verification of the concentration of chlorophyll standards by atomic absorption spectroscopy. Biochim. Biophys. Acta - Bioenerg. 975, 384-394 (1989).

\section{Acknowledgements}

This work was supported by an ERC Consolidator Grant "MatEnSAP" (682833), the U.K. Engineering and Physical Sciences Research Council (EP/L015978/1 and EP/G037221/1, nanoDTC, and a DTA studentship), the Christian Doppler Research Association, the OMV Group and a Royal Society Newton International Fellowship, the Cluster of Excellence RESOLV (EXC 1069) funded by the Deutsche Forschungsgemeinschaft (DFG) and the European Union's Horizon 2020 MSCA ITNEJD 764920 PHOTOBIOCAT. HAADF-STEM was carried out at the National Center of Electron Microscopy (NCEM), which is supported by the Office of Science, Office of Basic Energy Sciences of the U.S. Department of Energy under Contract No. DEAC02-05CH11231. Work at the Molecular Foundry was supported by the Office of Science, Office of Basic Energy Sciences of the U.S. Department of Energy under Contract No. DE-AC02-05CH11231. We would like to thank Dr Juan Fontecilla-Camps and Dr. Christine Cavazza for providing the $\mathrm{H}_{2}$ ase enzyme, Volker Hartmann for his contribution to PSII preparation and Prof Nicolas Plumeré, Mr. Charles Creissen, Dr. Shafeer Kalathil and Dr. Nina Heidary for valuable discussions. 


\section{Author contributions}

K.P.S., W.E.R., J.Z.Z. and E.R. conceived the research. K.P.S. prepared and characterised the electrodes and performed the electrochemical experiments. W.E.R. helped with the experiment design and supported the electrochemical experiments. J.W. synthesised the dpp dye. N.K. carried out HAADF-STEM and RRDE measurements. M.M.N. provided the PSII samples. A.R. synthesised the Pos polymer. K.P.S., W.E.R., N.K., J.Z.Z. and E.R. analysed the data. All authors contributed to the creation of the manuscript. E.R. supervised the work.

\section{Supporting information}

Supplementary information is available for this paper.

Reprints and permissions information is available at www.nature.com/reprints.

Correspondence and requests for materials should be addressed to E.R.

How to cite this article: Sokol, K. P. et al. Bias-free photoelectrochemical water splitting with photosystem II on a dye-sensitised photoanode wired to hydrogenase. Nat. Energy x, x (2018).

\section{Competing interests}

The authors declare no competing interests. 
Fig. 1 | Semi-artificial tandem PEC system for unassisted overall water splitting. a, Schematic representation of $1 \mathrm{O}-\mathrm{TiO}_{2}|\mathbf{d p p}|$ polymer-PSII photoanode wired to IO$\mathrm{ITO} \mid \mathrm{H}_{2}$ ase cathode (species size not drawn to scale). SEM images of $1 \mathrm{O}-\mathrm{TiO}_{2}$ photoanode architecture (top view and cross-section at $60^{\circ}$ tilt angle). b. Solution UVVis spectra of dpp $\left(0.15 \mu \mathrm{M}\right.$ in THF) and PSII $\left(0.005 \mathrm{mg} \mathrm{Chl} \mathrm{a} \mathrm{mL}^{-1}\right.$ in $\left.\mathrm{H}_{2} \mathrm{O}\right)$ with the

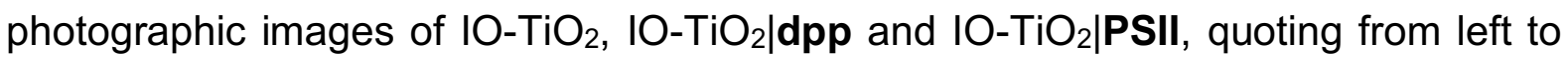
right (inset). Absorptions: $B_{y / x}$, chlorophyll a Soret-bands; $\beta$-Cat, $\beta$-carotene; $Q_{x / y}$, chlorophyll a lowest-energy bands; $\pi-\Pi^{*}$, dpp $\pi$-orbital intramolecular charge transfer. c, Electron-transfer pathway between PSII, $\mathrm{Pos}_{\mathbf{s}}$, dpp, IO-TiO, IO-ITO and $\mathbf{H}_{2}$ ase and the relevant redox potentials. Abbreviations: $\mathrm{Mn}_{4} \mathrm{Ca}$, oxygen-evolving complex (OEC); Tyrz, tyrosine; P680, pigment/primary electron donor; Pheo, pheophytin; $Q_{A} / Q_{B}$, plastoquinones; [NiFeSe], $\mathrm{H}_{2}$ ase active site; [4Fe4S], iron-sulphur clusters; all potentials reported vs. SHE at pH 6.5. Atom labels (PSII): C (grey), O (red), N (blue), $\mathrm{Mn}$ (violet), $\mathrm{Ca}$ (green), $\mathrm{Mg}$ (light green). Atom labels ( $\left.\mathrm{H}_{2} \mathbf{a s e}\right)$ : $\mathrm{S}$ (yellow), $\mathrm{Fe}$ (brown), $\mathrm{Ni}$ (green), Se (light orange).

Fig. 2 | PF-PEC of tandem PSII-dye photoanode. a, Chronoamperometry (0.1 V potential steps with $30 \mathrm{~s}$ dark and $10 \mathrm{~s}$ light cycles) for the determination of onset

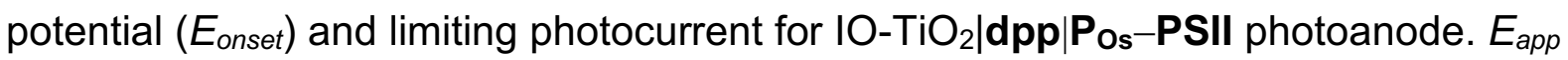
values (shown on top of the lines) are reported vs. SHE. Short irradiation times were used to minimise PSII photodegradation. b. Photocurrent density $(J)$ plotted as function of $E_{\text {app }}$ determined by stepped-potential chronoamperometry in a. Values of $J$ were taken at the end of illumination (baseline-corrected for background dark current). Error bars correspond to the standard deviation $(N=3)$. Control experiments omitting one of the components of the tandem photoanode are also presented in $\mathbf{a}$ and $\mathbf{b}$ (see figure legend). Conditions: PSII electrolyte solution, $\mathrm{pH}=6.5, \mathrm{~T}=25^{\circ} \mathrm{C}$. Counter and reference electrodes were a Pt wire and $\mathrm{Ag} / \mathrm{AgCl}(3 \mathrm{M} \mathrm{KCl})$, respectively. 
Fig. 3 | Photocurrent action spectra of tandem PSII-dye photoanode. a, Singlewavelength action spectra of the $1 \mathrm{O}-\mathrm{TiO}_{2}|\mathbf{d p p}| \mathrm{Pos}_{\mathrm{os}}-\mathrm{PSII}$ recorded with monochromatic light $\left(\lambda_{\text {scan }}\right)$ measured in $20 \mathrm{~nm}$ steps from $760 \mathrm{~nm}$ to $420 \mathrm{~nm}\left(E_{e}=6 \mathrm{~mW} \mathrm{~cm}^{-2}\right)$. The second left y-axis (grey) shows the corresponding external quantum efficiency (EQE) values. b, Dual-wavelength action spectra recorded with monochromatic light measured in $20 \mathrm{~nm}$ steps $\left(E_{e}=6 \mathrm{~mW} \mathrm{~cm}^{-2}\right)$ and a second simultaneous irradiation at a constant wavelength $\left(\lambda_{\text {const }}\right)=660 \mathrm{~nm}\left(E_{e}=4 \mathrm{~mW} \mathrm{~cm}^{-2}\right)$. The action spectra were normalised to equal photon flux at $500 \mathrm{~nm}\left(0.26 \mathrm{mmol} \mathrm{m}^{-2} \mathrm{~s}^{-1}\right)$. The control experiments (with $1 \mathrm{O}-\mathrm{TiO}_{2}|\mathbf{d p p}| \mathbf{P S I I}, \quad I \mathrm{O}-\mathrm{TiO}_{2}|\mathbf{d p p}| \mathbf{P}$ os and $I \mathrm{O}-\mathrm{TiO}_{2} \mid \mathbf{P o s}_{\mathrm{os}}-\mathbf{P S I I}$ photoanodes) are also given. The right $y$-axis (blue) refers to the UV-Vis spectra of background-corrected dpp and PSII immobilised on the $\mathrm{IO}^{-\mathrm{TiO}_{2}}$ electrodes (shaded in red and turquoise in the background). Conditions for all experiments: PSIl electrolyte solution, $\mathrm{pH}=6.5, \mathrm{~T}=25^{\circ} \mathrm{C}, E_{\text {app }}=0.5 \mathrm{~V}$ vs. SHE. The error bars correspond to the standard deviation $(N=3)$.

Fig. 4 | Overall water splitting in semi-artificial PEC cell. a, Chronoamperometry $(0.1 \mathrm{~V}$ voltage steps with $30 \mathrm{~s}$ dark and $30 \mathrm{~s}$ light cycles) of the two-electrode IO$\mathrm{TiO}_{2}|\mathbf{d p p}| \mathbf{P o s}_{\mathrm{o}}-\mathrm{PSII}||$ IO-ITO| $\mathbf{H}_{2}$ ase cell. Applied voltage $\left(U_{\text {app }}\right)$ values are shown on top of the lines. $\mathbf{b}$, Photocurrent density as a function of $U_{\text {app }}$ based on stepped-voltage $\left(\Delta U_{\text {app }}=0.1 \mathrm{~V}\right)$ chronoamperometry measurements for $1 \mathrm{O}-\mathrm{TiO}_{2}|\mathbf{d p p}| \mathrm{Pos}_{\mathrm{os}}-\mathrm{PSII} \| \mathrm{IO}-$ ITO| $\mathrm{H}_{2}$ ase determined in $\mathbf{a}$. Values of $J$ were taken at the end of illumination (baselinecorrected for background dark current). Error bars correspond to the standard deviation $(N=3)$. c, Quantification of $\mathrm{O}_{2}$ evolution $\left(\eta_{F}=88 \pm 12 \% ; N=6\right)$ of the photoanode after continuous $1 \mathrm{~h}$ illumination (AM $1.5 \mathrm{G}$ filter; $E_{e}=100 \mathrm{~mW} \mathrm{~cm}^{-2} ; \lambda>$ $420 \mathrm{~nm}$ ) with continuous stirring at $U_{a p p}=0.3 \mathrm{~V}$ (red curve). The amount of $\mathrm{H}_{2}\left(\eta_{F}=\right.$ $82 \pm 10 \% ; N=6$ ) was quantified by GC analysis. Control experiments in absence of PSII (cyan trace) and without irradiation (black trace) are also shown. Conditions: PSII electrolyte solution, $\mathrm{pH}=6.5, \mathrm{~T}=25^{\circ} \mathrm{C}$, continuous stirring, $\mathrm{N}_{2}$ atmosphere. 
a

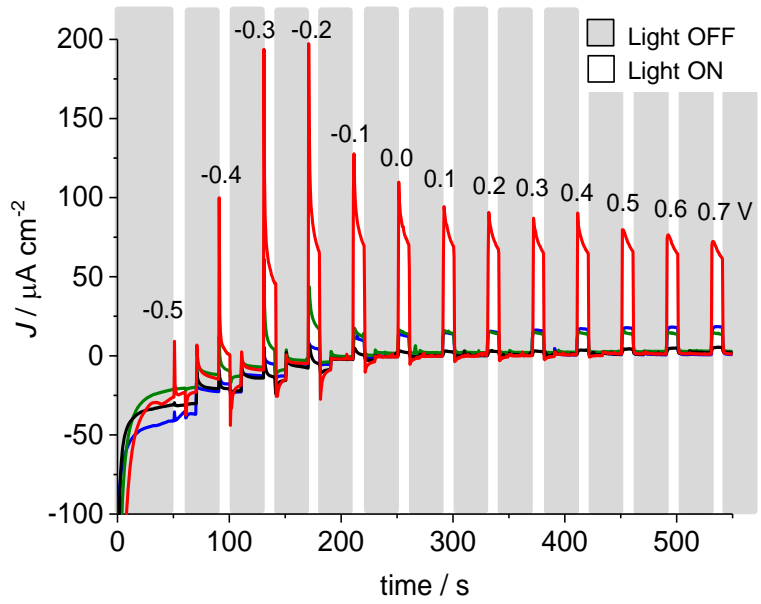

b

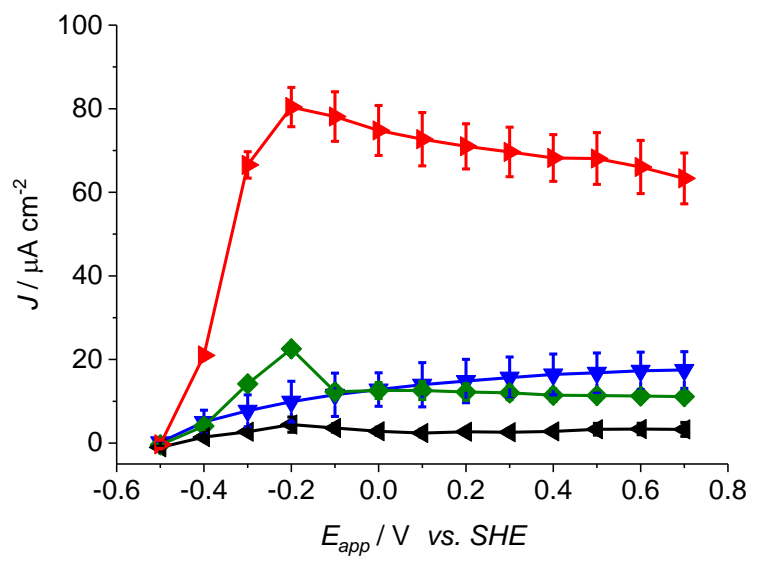

$\rightarrow-\mathrm{IO}-\mathrm{TiO}_{2}|\mathbf{d p p}| \mathrm{P}_{\mathrm{Os}^{-}}-\mathrm{PSII} \quad \longrightarrow \mathrm{IO}-\mathrm{TiO}_{2}|\mathbf{d p p}| \mathbf{P S I}$

$\rightarrow-\mathrm{IO}-\mathrm{TiO}_{2}|\mathbf{d p p}| \mathbf{P}_{\mathrm{Os}} \quad \longleftarrow-\mathrm{OO}-\mathrm{TiO}_{2} \mid \mathbf{P}_{\mathrm{Os}}-\mathrm{PSII}$ 
a Single $\lambda$ excitation

$\lambda_{\text {scan }}=420-760 \mathrm{~nm}$

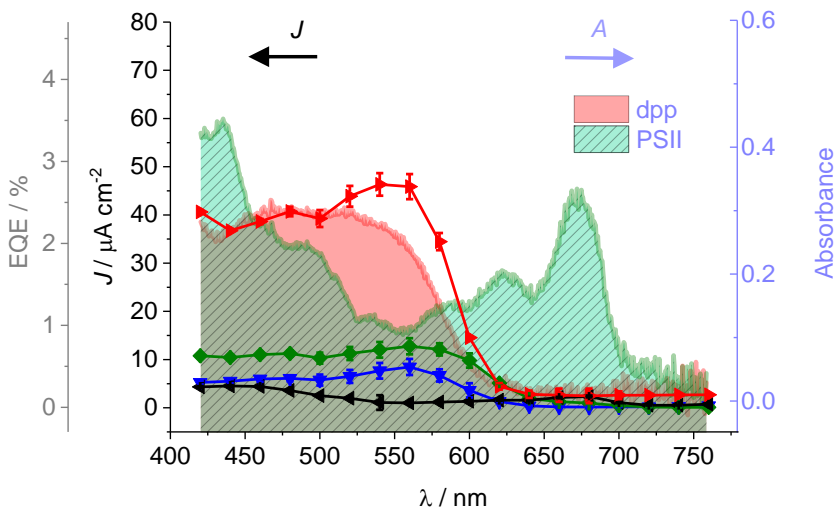

b Dual $\lambda$ excitation

$$
\begin{aligned}
& \lambda_{\text {scan }}=420-760 \mathrm{~nm} \\
& \lambda_{\text {const }}=660 \mathrm{~nm}
\end{aligned}
$$

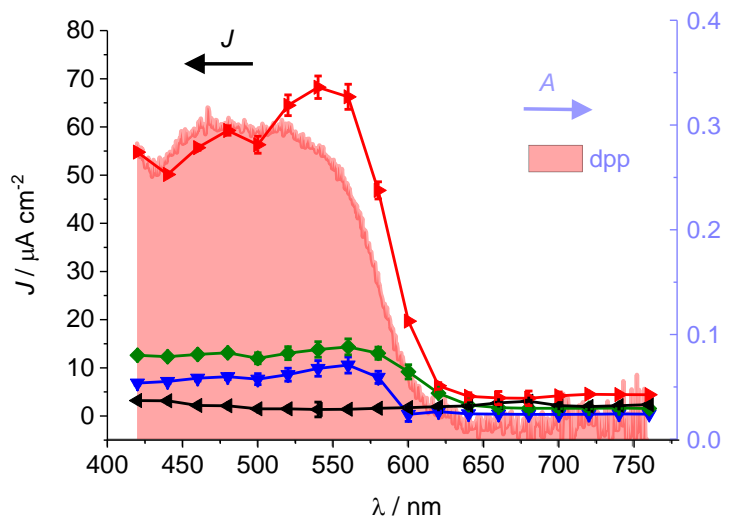

$\rightarrow-1 \mathrm{O}-\mathrm{TiO}_{2}|\mathbf{d p p}| \mathbf{P}_{\mathrm{Os}}-\mathrm{PSII}$

$\multimap-10-\mathrm{TiO}_{2}|\mathbf{d p p}| \mathrm{PSII}$

$\longrightarrow-\mathrm{OO}-\mathrm{TiO}_{2}|\mathbf{d p p}| \mathrm{P}_{\mathrm{os}}$

$\longleftarrow \mathrm{OO}-\mathrm{TiO}_{2} \mid \mathbf{P}_{\mathrm{Os}}-\mathrm{PSII}$ 


\section{$\mathbf{a}$}

b
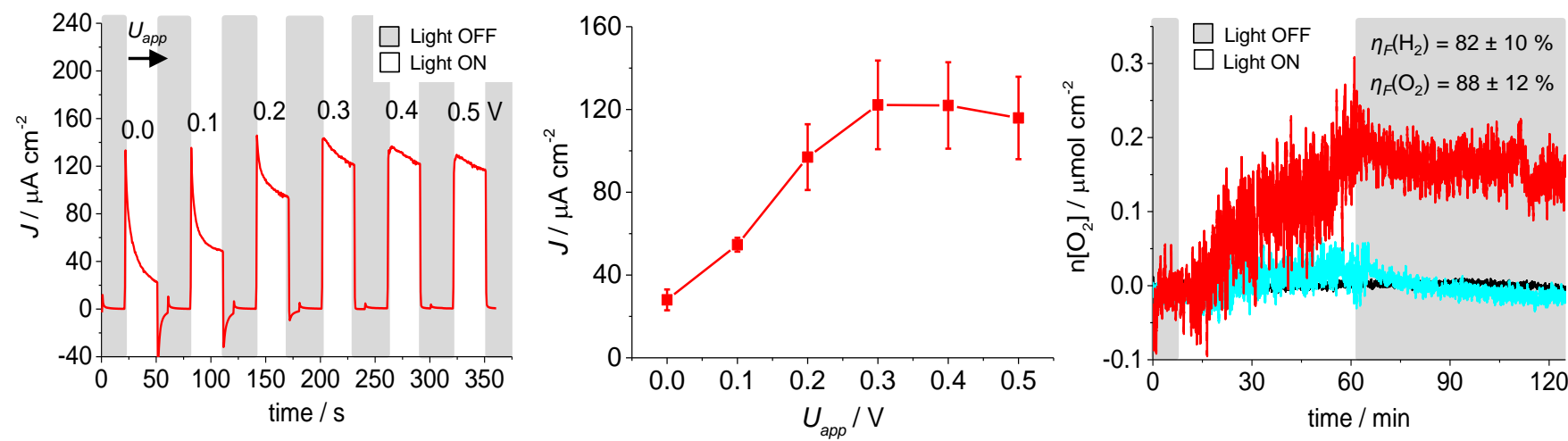